\title{
Association of a Reduction in Central Obesity and Phosphorus Intake With Changes in Urinary Albumin Excretion: The PREMIER Study
}

\author{
Alex Chang, MD, MS, ${ }^{1,2}$ Bryan C. Batch, MD, ${ }^{3,4}$ Heather L. McGuire, MD, ${ }^{5}$ \\ William M. Vollmer, PhD, ${ }^{6}$ Laura P. Svetkey, MD, MHS, ${ }^{4,7}$ Crystal C. Tyson, MD, ${ }^{4,7}$ \\ Anawin Sanguankeo, $M D,{ }^{2,8}$ Cheryl Anderson, $\mathrm{PhD}, \mathrm{MPH}, \mathrm{MS}^{9}{ }^{9}$ \\ Jessica Houston, MT, BS, ${ }^{2}$ and Lawrence J. Appel, $M D, M P H^{2}$
}

\begin{abstract}
Background: Excess adiposity and dietary factors may be important determinants of urinary albumin excretion (UAE).

Study Design: Observational analysis of PREMIER, a randomized trial designed to lower blood pressure using behavioral interventions (counseling on weight loss, healthy diet, and exercise).

Setting \& Participants: 481 participants with normal kidney function who provided adequate 24-hour urine collections at baseline and 6 months.

Predictors: Change in waist circumference; 24-hour urine sodium, potassium, and phosphorus excretion; and protein intake estimated from urea nitrogen.

Outcomes \& Measurements: The primary outcome was change in log-transformed 24-hour UAE over 6 months.

Results: After 6 months, the proportion of individuals with UAE $\geq 10 \mathrm{mg} / \mathrm{d}$ decreased from $18.7 \%$ to $12.7 \%(P<0.001)$. Changes in mean waist circumference $(-4.2 \pm 6.6[\mathrm{SD}] \mathrm{cm}), 24$-hour excretion of sodium $(-28.2 \pm 71.7 \mathrm{mmol} / \mathrm{d})$, potassium $(+8.4 \pm 27.8 \mathrm{mmol} / \mathrm{d})$, phosphorus $(-27.7 \pm 314.1 \mathrm{mg} / \mathrm{d})$, and protein intake $(-1.7 \pm 19.4 \mathrm{~g} / \mathrm{d})$ were observed. After adjustment for relevant covariates, the following variables were associated significantly with reduction in $\ln (\mathrm{UAE})$ in separate models: decrease in waist circumference $(P=$ $0.001)$, decrease in 24-hour urine phosphorus excretion $(P<0.001)$, and decrease in protein intake $(P=0.01)$. In a multivariable model including these 3 predictors, decreases in waist circumference $(P=0.002)$ and 24-hour urine phosphorus excretion $(P=0.03)$, but not change in protein intake $(P=0.5)$, remained associated significantly with reduction in $\operatorname{In}(\mathrm{UAE})$. These associations remained significant even after adjustment for changes in blood pressure and insulin resistance. Baseline UAE and metabolic syndrome modified the relationship of waist circumference with $\operatorname{In}(\mathrm{UAE})$; specifically, individuals with higher UAE and baseline metabolic syndrome experienced greater reductions in $\ln (\mathrm{UAE})$ from decreases in waist circumference.

Limitations: Observational study with potential for confounding.

Conclusions: In adults with normal kidney function, decreases in waist circumference and 24-hour urine phosphorus excretion are associated with reductions in UAE. These findings support the rationale for clinical trials to determine whether reducing dietary phosphorus intake or waist circumference could prevent chronic kidney disease or slow its progression.
\end{abstract}

Am J Kidney Dis. 62(5):900-907. () 2013 by the National Kidney Foundation, Inc.

INDEX WORDS: Weight loss; waist circumference; protein; phosphorus; urinary albumin excretion.

$\mathbf{E}^{\prime}$ levated levels of urinary albumin excretion (UAE) are associated with increased risk of cardiovascular events, end-stage renal disease, and mortality even at levels as low as $10 \mathrm{mg} / \mathrm{d} .{ }^{1-5}$ Cohort studies of individuals with diabetes or vascular disease have shown that reductions in UAE are associated with decreased risk of cardiovascular outcomes, ${ }^{6}$ kidney disease outcomes, and mortality. ${ }^{7}$ Potentially modifiable lifestyle factors that may affect UAE include excess adiposity ${ }^{8-12}$ and diet. ${ }^{12-14}$ In a few small trials, weightloss interventions reduced proteinuria and albuminuria; however, most of these studies did not assess changes in diet, including protein and phosphorus intake..$^{11,15-19}$ Hence, it is uncertain whether the benefit of these inter-
From the ${ }^{1}$ Division of Nephrology and ${ }^{2}$ Welch Center for Prevention, Epidemiology, and Clinical Research, Johns Hopkins University, Baltimore, MD; ${ }^{3}$ Division of Endocrinology, Metabolism, and Nutrition and ${ }^{4}$ Sarah W. Stedman Nutrition and Metabolism Center, Duke University Medical Center, Durham, NC; ${ }^{5}$ Nephrology Department, Billings Clinic, Billings, MT; ${ }^{6}$ Center for Health Research, Kaiser Permanente Northwest, Portland, OR; ${ }^{7}$ Division of Nephrology, Duke University Medical Center, Durham, NC; ${ }^{8}$ Department of Preventive and Social Medicine, Faculty of Medicine Siriraj Hospital, Mahidol University, Bang- kok, Thailand; and ${ }^{9}$ Department of Family and Preventive Medicine, University of California San Diego, San Diego, CA. Received January 4, 2013. Accepted in revised form April 25, 2013. Originally published online July 1, 2013.

Address correspondence to Alex Chang, MD, MS, Johns Hopkins University, Division of Nephrology, 1830 Monument St, Ste 416, Baltimore, MD 21205. E-mail: achang43@jhmi.edu

(C) 2013 by the National Kidney Foundation, Inc.

0272-6386/\$36.00

http://dx.doi.org/10.1053/j.ajkd.2013.04.022 
ventions resulted from weight loss or changes in nutrient intake. Only one study of 30 individuals with overt proteinuria reported changes in 24-hour urine urea nitrogen excretion (no significant change during the intervention) and found that a mean weight loss of $4.1 \%$ resulted in a mean decrease in proteinuria of $31.2 \% .^{20}$ Furthermore, little is known about the impact of weight loss on UAE in individuals without overt kidney disease.

Diet may play an important role in UAE because dietary patterns characterized by high intake of red meat, saturated fats, and sweets have been associated with incident microalbuminuria. ${ }^{12,13}$ Although studies of protein restriction in individuals with chronic kidney disease (CKD) have suggested potential benefits on slowing the progression of $\mathrm{CKD},{ }^{21}$ potential risks of high protein intake in persons with normal kidney function remain uncertain. ${ }^{22-24}$ One dietary factor intrinsically linked to protein is phosphorus, which at high levels of consumption can cause kidney injury in animal CKD models (independent of protein). ${ }^{25} \mathrm{Al}-$ though serum phosphorus level has been found to be associated with low-grade albuminuria, ${ }^{26}$ cardiovascular events, and mortality, ${ }^{27,28}$ little is known about risk associated with 24-hour urine phosphorus excretion, which may more adequately reflect dietary intake. ${ }^{29}$

The goal of this study was to examine whether changes in central obesity and dietary factors, estimated from 24-hour urine collections, were associated with changes in UAE using data from a randomized controlled trial of dietary intervention in patients with prehypertension or stage I hypertension.

\section{METHODS}

\section{Study Population}

The PREMIER Study is a completed 18-month multicenter randomized trial that was designed to test the effect of 2 behavioral interventions on blood pressure (BP) in adults with prehypertension or stage I hypertension (systolic BP, 120-159 mm Hg; diastolic BP, 80-95 mm Hg). Participants were eligible if they were not taking antihypertensive agents and had systolic BP of 120-159 $\mathrm{mm} \mathrm{Hg}$ or diastolic BP of $80-95 \mathrm{~mm} \mathrm{Hg}$. Exclusion criteria included use of BP medications, weight-loss or steroid medications, diabetes, decreased kidney function (estimated glomerular filtration rate $<60 \mathrm{~mL} / \mathrm{min}$ using the Cockcroft-Gault equation), history of a cardiovascular event, congestive heart failure, angina, cancer diagnosis or treatment in the past 2 years, consumption of more than 21 alcoholic drinks per week, and pregnancy. More detailed information about the study methods and main results have been published. ${ }^{30}$

Eligible participants were randomly assigned to 1 of 3 groups: (1) an "established" group that received behavioral counseling on achieving weight loss of at least $15 \mathrm{lb}$ at 6 months (for those with body mass index $\geq 25 \mathrm{~kg} / \mathrm{m}^{2}$ ), engaging in 180 or more minutes per week of moderate-intensity physical activity, and consuming $\leq 100 \mathrm{mEq} / \mathrm{d}$ of dietary sodium; (2) an "established-plus-Dietary Approaches to Stop Hypertension (DASH)" group that received the same recommendations as the established group and counseling on the DASH dietary pattern; and (3) an "advice-only" comparison group that received a single 30-minute individual advice session at the time of randomization with verbal and written instructions on weight loss, increasing physical activity, sodium reduction, and the DASH dietary pattern. Both the established and established-plus-DASH groups received group counseling weekly for the first 8 weeks, then biweekly through 6 months, that emphasized reduced total caloric intake and increased physical activity. The established group did not have goals for fruit, vegetable, and dairy intake; goals for saturated fat and total intake were set at $\leq 10 \%$ and $\leq 30 \%$ of energy intake, respectively. The established-plus-DASH group received additional instruction on following the DASH dietary pattern, which emphasized increased consumption of fruits and vegetables (9-12 servings daily), low-fat dairy products (2-3 servings daily), and reduced intake of saturated ( $\leq 7 \%$ of energy) and total fats ( $\leq 25 \%$ of energy).

\section{Measurements}

Baseline and 6-month measurements were obtained by staff who were masked to randomization assignment. BP measurements were obtained by trained certified individuals using a random-zero sphygmomanometer following a standardized protocol. ${ }^{9}$ All baseline BP measurements were obtained before randomization. BP at baseline and 6 months was defined as an average of 6-8 readings.

Twenty-four-hour urine collections were obtained at the baseline and 6-month visits. Collections with urine volume $<500 \mathrm{~mL}$ or collection period less than 22 or more than 26 hours were repeated. Urinary sodium, potassium, phosphorus, urea nitrogen, and creatinine were measured in a central laboratory on a Hitachi 917 analyzer using Roche reagents. Albumin was measured on urine samples that were stored at $-70^{\circ} \mathrm{C}$ for 3-5 years before analysis using a Tina-Quant (Roche) albumin assay. All urine laboratory values were standardized to 24-hour measurements. Dietary protein intake was estimated using the Maroni equation ${ }^{31-34}$ : estimated protein intake $=$ [urinary urea nitrogen + (weight in $\mathrm{kg} \times$ $0.031 \mathrm{~g}$ nitrogen $/ \mathrm{kg} / \mathrm{d})] \times 6.25$.

Blood samples for measurement of glucose, insulin, and lipids were obtained by venipuncture in the morning after an overnight fast. Weight was measured to the nearest $0.1 \mathrm{~kg}$ twice at each study visit and averaged, using a calibrated scale with individuals in light indoor clothing and no shoes. Height was measured using a wall-mounted stadiometer. Waist circumference was measured using a tape according to a standardized protocol at baseline and 6 months.

Metabolic syndrome was defined by National Cholesterol Education Program (NCEP) criteria, which required 3 or more of the following: waist circumference $>102 \mathrm{~cm}$ (men) or $>88 \mathrm{~cm}$ (women); triglyceride level $\geq 150 \mathrm{mg} / \mathrm{dL}$; high-density lipoprotein cholesterol level $<40 \mathrm{mg} / \mathrm{dL}$ (men) or $<50 \mathrm{mg} / \mathrm{dL}$ (women); BP $\geq 130 / \geq 85 \mathrm{~mm} \mathrm{Hg}$; and fasting glucose $\geq 110 \mathrm{mg} / \mathrm{dL}$. ${ }^{35}$ Homeostasis model assessment of insulin resistance (HOMA-IR) was calculated by the formula: (glucose $\times$ insulin) $/ 405 .{ }^{36}$ Supplement use was measured by 2 unannounced 24-hour dietary recalls conducted by telephone interviews ( 1 on a weekday and the other on a weekend day) only during the baseline visit.

\section{Analysis}

Unpaired $t$ tests or Pearson $\chi^{2}$ tests were used to compare continuous and categorical baseline characteristics between individuals with elevated UAE ( $\geq 10 \mathrm{mg} / \mathrm{d})$ and those without elevated UAE. Median UAE and elevated UAE status at 6 months were compared to the baseline examination using paired $t$ test and McNemar test. UAE was natural log transformed due to its skewed distribution and expressed as $\ln (\mathrm{UAE})$ in longitudinal analyses examining associations between changes in waist circumference and dietary biomarkers with change in $\ln (\mathrm{UAE})$. To minimize the influence of over- and undercollection of urine on this analysis, we 
only included individuals with 24-hour urine creatinine coefficients of variation $(\mathrm{CVs})<25 \%$, which is the upper limit of the intraindividual CV found in previous studies. ${ }^{37}$ This substantially improved correlation between the baseline and 6-month 24-hour urine creatinine measurements from 0.65 to 0.85 .

Covariates including age, sex, race, cohort (participants were recruited in 4 waves), site, current smoking, treatment group assignment, baseline systolic BP, $\ln (\mathrm{UAE})$, and metabolic syndrome were considered in our base model, which was created using backwards stepwise regression, retaining variables with $P<$ 0.1 . We then created separate models adding change in waist circumference and each dietary measure (estimated protein intake and 24-hour urinary sodium, potassium, sodium to potassium ratio, and phosphorus) individually to the base model. We used waist circumference rather than weight because waist circumference better reflects central adiposity. ${ }^{38}$ Covariates were standardized in these models to facilitate relative comparisons among regression coefficients. Beta coefficients then were back-transformed and presented as percentage of change in UAE associated with a 1-SD change in the corresponding predictor variable.

We then created multivariable models adding significant predictors $(P<0.05)$ to the base model, which included age, race, site, current smoking, baseline systolic $\mathrm{BP}$, and $\ln (\mathrm{UAE})$ : multivariable model 1: base model plus change in waist circumference, change in protein intake, and change in 24-hour urine phosphorus excretion; multivariable model 2: base model plus change in waist circumference and change in protein intake; and multivariable model 3: base model plus change in waist circumference and change in 24-hour urine phosphorus excretion. These latter 2 models were constructed because changes in protein intake and 24-hour urine phosphorus excretion were correlated strongly ( $r=$ $0.58 ; P<0.001)$. To test for mediators, we included change in systolic BP and change in HOMA-IR to multivariable model 1. We also tested for effect modification by baseline systolic BP, baseline UAE, and baseline metabolic syndrome by adding relevant interaction terms to multivariable model 1 .

Sensitivity analyses were performed using different inclusion criteria: (1) including those with 24-hour urine creatinine CV $<40 \%$ (instead of 25\%), and (2) including individuals with 24-hour urine collections within $30 \%$ of expected creatinine values (for men, $22.1 \mathrm{mg} / \mathrm{kg}$; women, $17.2 \mathrm{mg} / \mathrm{kg}$ ). ${ }^{34,39}$ We also repeated analyses adjusting for self-reported baseline use of calcium and vitamin D supplements. For all analyses, we used complete case analysis, only including participants with complete data for each model using Stata, version 11.1 (StataCorp LP).

\section{RESULTS}

\section{Population Characteristics}

A total of 810 participants were enrolled in the PREMIER trial, and 598 individuals provided complete 24-hour urine samples at baseline and at the 6-month visit. After exclusion of individuals who had 24-hour urine creatinine $\mathrm{CV} \geq 25 \%$ ( $\mathrm{n}=95$ ) and individuals missing data for 24-hour urine dietary markers $(n=16)$ or waist circumference $(n=6), 481$ participants were included in our analyses. A higher proportion of African Americans (42\% vs 31\%; $P=$ 0.03 ) were excluded due to urine collections with CVs $\geq 25 \%$; otherwise, there were no other significant differences between those with adequate and inadequate urine collections. Table 1 lists baseline characteristics by elevated UAE status ( $\geq 10 \mathrm{mg} / \mathrm{d}$ ). Individu-
Table 1. Baseline Characteristics by Presence or Absence of Elevated UAE

\begin{tabular}{|c|c|c|c|}
\hline & $\begin{array}{l}\text { Elevated UAE } \\
\quad(n=90)\end{array}$ & $\begin{array}{l}\text { Normal UAE } \\
(\mathrm{n}=391)\end{array}$ & $P$ \\
\hline Age (y) & $50.9 \pm 8.6$ & $51.0 \pm 8.5$ & 0.9 \\
\hline Female sex & $57 \%$ & $62 \%$ & 0.4 \\
\hline African American & $42 \%$ & $29 \%$ & 0.02 \\
\hline $\mathrm{BMI}\left(\mathrm{kg} / \mathrm{m}^{2}\right)$ & $34.7 \pm 6.2$ & $32.5 \pm 5.6$ & 0.002 \\
\hline $\begin{array}{l}\text { Waist circumference } \\
(\mathrm{cm})\end{array}$ & $114.0 \pm 17.6$ & $106.9 \pm 14.5$ & $<0.001$ \\
\hline $\mathrm{SBP}(\mathrm{mm} \mathrm{Hg})$ & $138.6 \pm 9.3$ & $133.9 \pm 9.6$ & $<0.001$ \\
\hline DBP (mm Hg) & $85.5 \pm 4.3$ & $84.5 \pm 4.1$ & 0.04 \\
\hline Hypertension & $51 \%$ & $34 \%$ & 0.002 \\
\hline Glucose (mg/dL) & $102.4 \pm 16.5$ & $99.0 \pm 13.9$ & 0.05 \\
\hline Insulin $(\mu \mathrm{U} / \mathrm{mL})$ & $17.8 \pm 11.3$ & $13.9 \pm 9.7$ & 0.001 \\
\hline $\begin{array}{l}\text { LDL cholesterol } \\
\qquad(\mathrm{mg} / \mathrm{dL})\end{array}$ & $136.2 \pm 30.9$ & $135.9 \pm 34.8$ & 0.9 \\
\hline HOMA-IR & $4.7 \pm 4.0$ & $3.6 \pm 3.6$ & 0.01 \\
\hline Current smoking & $9 \%$ & $3 \%$ & 0.01 \\
\hline Metabolic syndrome & $61 \%$ & $51 \%$ & 0.07 \\
\hline 24-h UAE (mg/d) & $22.0[13.7-45.2]$ & $3.2[2.1-5.0]$ & $<0.001$ \\
\hline $\begin{array}{l}\text { Estimated protein } \\
\text { intake }^{\mathrm{a}}(\mathrm{g} / \mathrm{d})\end{array}$ & $95.7 \pm 27.3$ & $90.2 \pm 24.4$ & 0.06 \\
\hline Urine $\mathrm{Na}: \mathrm{K}$ ratio & $3.2 \pm 1.3$ & $2.7 \pm 1.2$ & 0.003 \\
\hline $\begin{array}{l}\text { 24-h urine } \mathrm{Na} \\
(\mathrm{mmol} / \mathrm{d})\end{array}$ & $198.0 \pm 78.3$ & $169.4 \pm 69.1$ & $<0.001$ \\
\hline $\begin{array}{l}\text { 24-h urine K } \\
\qquad(\mathrm{mmol} / \mathrm{d})\end{array}$ & $65.9 \pm 22.4$ & $67.5 \pm 24.5$ & 0.6 \\
\hline 24-h urine $P(\mathrm{mg} / \mathrm{d})$ & $1007.8 \pm 372.4$ & $914.1 \pm 325.6$ & 0.02 \\
\hline
\end{tabular}

Note: Elevated UAE is $\geq 10 \mathrm{mg} / \mathrm{d}$. Values for continuous variables are given as mean \pm standard deviation or median [interquartile range]. Conversion factors for units: glucose in $\mathrm{mg} / \mathrm{dL}$ to $\mathrm{mmol} / \mathrm{L}, \times 0.05551$; $\mathrm{LDL}$ cholesterol in $\mathrm{mg} / \mathrm{dL}$ to $\mathrm{mmol} / \mathrm{L}, \times 0.02586$.

Abbreviations: BMI, body mass index; DBP, diastolic blood pressure; HOMA-IR, homeostasis model assessment of insulin resistance; K, potassium; LDL, low-density lipoprotein; $\mathrm{Na}$, sodium; P, phosphorus; SBP, systolic blood pressure; UAE, urinary albumin excretion.

${ }^{\mathrm{a}}$ Estimated protein intake $=$ (urinary urea nitrogen $+0.031 \mathrm{~g}$ nitrogen/kg body weight) $\times 6.25$.

als with elevated UAE were more likely to be African American, obese, and current smokers and have hypertension. They also had higher mean waist circumference, systolic and diastolic BPs, insulin resistance, 24-hour urine sodium excretion, sodium/potassium ratios, and 24-hour urine phosphorus excretion (Table 1).

\section{Changes in UAE and Measures of Obesity and Diet After 6 Months}

After 6 months, median UAE decreased from 4.0 (interquartile range, 2.3-7.4) to 3.0 (interquartile range, 1.9-5.5; $P<0.001$ ) with no significant differences between treatment groups. Overall, the proportion of individuals with elevated UAE $\geq 10 \mathrm{mg} / \mathrm{d}$ decreased 
Table 2. Cross-Tabulation of Baseline and 6-Month UAE Categories

\begin{tabular}{lccr}
\hline & \multicolumn{3}{c}{ 6-Month UAE } \\
\cline { 2 - 4 } Baseline UAE & $<10 \mathrm{mg} / \mathrm{d}$ & $\mathbf{1 0 - 2 9 . 9 ~ m g / d ~}$ & $\geq 30 \mathrm{mg} / \mathrm{d}$ \\
\hline & & & \\
$<10 \mathrm{mg} / \mathrm{d}$ & $379(78.8)^{\mathrm{a}}$ & $11(2.3)^{\mathrm{b}}$ & $1(0.2)^{\mathrm{b}}$ \\
$10-29.9 \mathrm{mg} / \mathrm{d}$ & $37(7.7)^{\mathrm{c}}$ & $18(3.7)^{\mathrm{a}}$ & $4(0.8)^{\mathrm{b}}$ \\
$\geq 30 \mathrm{mg} / \mathrm{d}$ & $4(0.8)^{\mathrm{c}}$ & $11(2.3)^{\mathrm{c}}$ & $16(3.3)^{\mathrm{a}}$ \\
\hline
\end{tabular}

Note: $\mathrm{N}=481$. Values are given as number (percentage). Abbreviation: UAE, urinary albumin excretion.

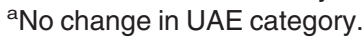

bWorsening in UAE category.

'Improvement in UAE category.

from $18.7 \%$ to $12.7 \%(P<0.001)$, and findings were similar using a UAE cutoff of $\geq 30 \mathrm{mg} / \mathrm{d}$ ( $6.4 \%$ to $4.4 \%$; $P=0.03)$. When defined in categories of $\mathrm{UAE}<10$, $10-29.9$, and $\geq 30 \mathrm{mg} / \mathrm{d}, 52$ individuals had improvements in UAE category while 16 individuals changed to worse UAE categories after 6 months (Table 2). Over 6 months, waist circumference changed by a mean of $-4.2 \pm 6.6(\mathrm{SD}) \mathrm{cm}$ (Table 3). Changes in mean 24-hour urinary sodium $(-28.2 \pm 71.7 \mathrm{mmol} / \mathrm{d})$, potassium $(8.4 \pm 27.8 \mathrm{mmol} / \mathrm{d})$, and phosphorus $(-27.7 \pm$ $314.1 \mathrm{mg} / \mathrm{d})$ excretion and protein intake $(-1.7 \pm 19.4$ $\mathrm{g} / \mathrm{d})$ also were observed.

\section{Associations Between Changes in Obesity and Dietary Measures With Change in In(UAE)}

Table 4 shows percentage changes in UAE for every 1-SD decrease in predictors in an analysis adjusted for age, site, African American race, current smoking, baseline systolic BP, and baseline $\ln (\mathrm{UAE})$. In individual models, every 1-SD reduction $(6.6 \mathrm{~cm})$ in waist circumference was associated with a $-10.9 \%$ change $(95 \%$ confidence interval $[\mathrm{CI}],-16.6 \%$ to $-5.2 \% ; P=0.001)$ in $\mathrm{UAE}$; every $1-\mathrm{SD}$ reduction in 24-hour urine phosphorus $(314 \mathrm{mg} / \mathrm{d})$ and protein intake $(19 \mathrm{~g} / \mathrm{d})$ was associated with $-10.9 \%(95 \% \mathrm{CI}$, $-16.4 \%$ to $-4.9 \% ; P<0.001)$ and $-8.1 \%(95 \% \mathrm{CI}$, $-13.9 \%$ to $-2.0 \%$; $P=0.01)$ changes in UAE, respectively, in these individual models. Changes in 24-hour urine sodium, potassium, and sodium/potassium ratio were not associated significantly with changes in UAE (Table 4).

In multivariable model 1 , decreases in waist circumference $(-9.9 \%$ change in UAE per 1-SD decrease; $95 \% \mathrm{CI},-15.6 \%$ to $-3.8 \% ; P=0.002)$ and 24 -hour urine phosphorus $(-8.2 \%$ change in UAE per 1-SD decrease; $95 \% \mathrm{CI},-15.2 \%$ to $-0.6 \% ; P=0.03$ ) remained significantly associated with change in UAE, whereas decrease in estimated protein intake was not (Table 5). The association between decrease in 24hour urine phosphorus and change in UAE was slightly stronger $(-9.8 \%$ change in UAE per 1-SD decrease; $95 \% \mathrm{CI},-15.4 \%$ to $-3.8 \% ; P=0.002)$ in multivariable model 2, which does not include change in protein intake $(r=0.58 ; P<0.001$ for correlation with 24-hour urine phosphorus). Decrease in protein intake was associated significantly with a $-7.7 \%$ change in UAE per 1-SD decrease $(95 \% \mathrm{CI},-13.4 \%$ to $-1.5 \% ; P=0.02$ ) in multivariable model 3 , which does not include change in 24-hour urine phosphorus (Table 3). Thus, the association between protein intake and UAE was largely explained by 24-hour urine phosphorus, whereas the association between 24-hour urine phosphorus and UAE was not explained solely by protein intake. When changes in systolic BP or insulin resistance were added to multivariable model 1 , decreases in waist circumference and 24-hour urine phosphorus remained significantly associated with reductions in UAE.

In tests for interaction, we found that the effect of decreased waist circumference on change in UAE was modified by baseline metabolic syndrome $(P=0.01)$ and baseline UAE $(P=0.02)$, but not baseline systolic BP $(P=0.5$; Fig 1$)$. In subgroup analyses adjusted for the same covariates as multivariable model 1, individuals in the highest tertile of baseline UAE ( $\geq 5.5 \mathrm{mg} / \mathrm{d})$ had a $-16.4 \%(95 \% \mathrm{CI},-25.1 \%$ to $-6.8 \% ; P=0.001$ ) change in UAE for every $1-\mathrm{SD}$ decrease in waist circumference compared to $-6.9 \%$ (95\% CI, $-15.7 \%$ to $2.8 \% ; P=0.2$ ) for the middle tertile $(2.7-5.4 \mathrm{mg} / \mathrm{d})$ and $-4.9 \%(95 \% \mathrm{CI},-15.6 \%$ to $7.1 \% ; P=0.4)$ for the lowest tertile $(<2.7 \mathrm{mg} / \mathrm{d})$ of baseline UAE. Similarly, individuals who had metabolic syndrome at baseline had a $-17.2 \%(95 \% \mathrm{CI}$, $-23.9 \%$ to $-9.9 \% ; P<0.001)$ change in UAE for every 1-SD decrease in waist circumference, whereas no association $(P=0.8)$ was observed for individuals without metabolic syndrome. Baseline metabolic syndrome, baseline UAE, and baseline systolic BP did

Table 3. Changes in Obesity and Dietary Measures Over 6 Months

\begin{tabular}{lc}
\hline \multicolumn{1}{c}{ Measure } & Change \\
\hline Waist circumference $(\mathrm{cm})$ & $-4.2 \pm 6.6$ \\
Weight $(\mathrm{kg})$ & $-4.3 \pm 5.4$ \\
24-h urine $\mathrm{Na}(\mathrm{mmol} / \mathrm{d})$ & $-28.2 \pm 71.7$ \\
24-h urine $\mathrm{K}(\mathrm{mmol} / \mathrm{d})$ & $+8.4 \pm 27.8$ \\
24-h urine P $(\mathrm{mg} / \mathrm{d})$ & $-27.7 \pm 314.1$ \\
Urine Na:K ratio & $-0.58 \pm 1.31$ \\
Estimated protein intake $(\mathrm{g} / \mathrm{d})^{\mathrm{a}}$ & $-1.7 \pm 19.4$ \\
\hline
\end{tabular}

Note: Values are given as mean \pm standard deviation. Abbreviations: K, potassium; Na, sodium; P, phosphorus.

${ }^{a}$ Estimated protein intake $=$ (urinary urea nitrogen $+0.031 \mathrm{~g}$ nitrogen $/ \mathrm{kg}$ body weight) $\times 6.25$. 
Table 4. Changes in UAE Associated With Decreases in Waist Circumference and Dietary Measures

\begin{tabular}{|c|c|c|c|c|c|c|c|c|}
\hline \multirow[b]{2}{*}{ Decrease } & \multicolumn{2}{|c|}{ Individual Models } & \multicolumn{2}{|c|}{ Multivariable Model 1} & \multicolumn{2}{|c|}{ Multivariable Model 2} & \multicolumn{2}{|c|}{ Multivariable Model 3} \\
\hline & $\triangle \mathrm{UAE}(95 \% \mathrm{Cl})$ & $P$ & $\triangle \mathrm{UAE}(95 \% \mathrm{Cl})$ & $P$ & $\triangle$ UAE $(95 \% \mathrm{Cl})$ & $P$ & $\triangle \mathrm{UAE}(95 \% \mathrm{Cl})$ & $P$ \\
\hline $\begin{array}{l}\text { Waist circumference } \\
\quad(\text { per } 6.6 \mathrm{~cm})\end{array}$ & $-10.9(-16.6$ to -5.2$)$ & 0.001 & $-9.9(-15.6$ to -3.8$)$ & 0.002 & $-9.9(-15.4$ to -3.8$)$ & 0.002 & $-10.6(-16.3$ to -4.6$)$ & 0.001 \\
\hline $\begin{array}{l}\text { 24-h urine } P \text { (per } \\
314.1 \mathrm{mg} / \mathrm{d} \text { ) }\end{array}$ & $-10.9(-16.4$ to -4.9$)$ & $<0.001$ & $-8.2(-15.2$ to -0.6$)$ & 0.03 & $-9.8(-15.4$ to -3.8$)$ & 0.002 & & \\
\hline $\begin{array}{l}\text { Protein intake (per } \\
\quad 19.4 \mathrm{~g} / \mathrm{d})\end{array}$ & $-8.1(-13.9$ to -2.0$)$ & 0.01 & $-2.9(-10.3$ to 5.0$)$ & 0.5 & & & $-7.7(-13.4$ to -1.5$)$ & 0.02 \\
\hline $\begin{array}{l}\text { 24-h urine } \mathrm{Na} \text { (per } \\
71.7 \mathrm{mmol} / \mathrm{d} \text { ) }\end{array}$ & $-4.7(-10.7$ to 1.7$)$ & 0.1 & & & & & & \\
\hline $\begin{array}{l}\text { 24-h urine K (per } \\
27.8 \mathrm{mmol} / \mathrm{d} \text { ) }\end{array}$ & $-2.3(-8.5$ to 4.4$)$ & 0.5 & & & & & & \\
\hline $\begin{array}{l}\text { Na:K ratio (per } 1.3 \\
\text { mmol/mmol) }\end{array}$ & $-1.5(-7.8$ to 5.1$)$ & 0.6 & & & & & & \\
\hline
\end{tabular}

Note: $\mathrm{N}=481$. Each model was adjusted for age, site, African American race, current smoking, baseline systolic blood pressure, and In(UAE). Covariates were standardized in these models to facilitate relative comparisons between regression coefficients. Beta coefficients were then backtransformed and are presented as percent change in UAE associated with a 1-SD decrease in the corresponding predictor variable.

Abbreviations and definitions: $\mathrm{Cl}$, confidence interval, $\triangle \mathrm{UAE}$, change in $\mathrm{UAE} ; \mathrm{K}$, potassium; Na, sodium; $\mathrm{P}$, phosphorus; UAE, urinary albumin excretion.

not modify the effect of changes in 24-hour urine phosphorus or protein intake on UAE.

Sensitivity analyses using different inclusion criteria (24-hour urine creatinine $\mathrm{CV}<40 \%$; 24-hour urine creatinine values within $30 \%$ of expected sexspecific values ${ }^{34,39}$ ) showed similar effect sizes and associations as our primary analysis, as did analyses in which we adjusted for baseline calcium and vitamin D supplement use (data not shown).

\section{DISCUSSION}

In this cohort of mostly overweight and obese individuals with prehypertension or stage I hypertension and normal kidney function, we found that reductions in waist circumference and 24-hour urine phos-

Table 5. Multivariable Model 1 Adjusted for Potential Mediators

\begin{tabular}{lcl}
\hline \multicolumn{1}{c}{ Decrease } & \multicolumn{1}{c}{$\Delta$ UAE $(95 \% \mathrm{Cl})$} & \multicolumn{1}{c}{$\boldsymbol{P}$} \\
\hline $\begin{array}{l}\text { Waist circumference } \\
\quad \text { per } 6.6 \mathrm{~cm})\end{array}$ & $-10.5(-16.6$ to -4.0$)$ & 0.002 \\
24-h urine P $($ per $314.1 \mathrm{mg} / \mathrm{d})$ & $-8.6(-15.6$ to -1.0$)$ & 0.03 \\
Protein intake $($ per $19.4 \mathrm{~g} / \mathrm{d})$ & $-2.9 \%(-10.4$ to 5.1$)$ & 0.5 \\
SBP $($ per $9.2 \mathrm{~mm} \mathrm{Hg})$ & $+1.7(-5.3$ to 9.3$)$ & 0.6 \\
HOMA-IR $($ per 3.2 U) & $+3.3(-3.2$ to 10.3$)$ & 0.3 \\
\hline
\end{tabular}

Note: $\mathrm{n}=473$. Potential mediators are changes in SBP and HOMA-IR. Adjusted for age, site, African American race, baseline SBP, current smoking, and baseline $\operatorname{In}(\mathrm{UAE})$. Covariates were standardized in these models to facilitate relative comparisons between regression coefficients. Beta coefficients were then back-transformed and are presented as percent change in UAE associated with a 1-SD decrease in the corresponding predictor variable.

Abbreviations and definitions: $\mathrm{Cl}$, confidence interval; $\triangle \mathrm{UAE}$, change in UAE; HOMA-IR, homeostasis model assessment of insulin resistance; $\mathrm{P}$, phosphorus; $\mathrm{SBP}$, systolic blood pressure; UAE, urinary albumin excretion. phorus excretion were associated significantly with decreases in UAE. Our findings suggest that reducing central adiposity and phosphorus intake could be an important strategy in reducing UAE. In our study, the association between change in waist circumference and UAE was greatest in those with baseline metabolic syndrome and higher baseline UAE. This latter finding is consistent with a meta-analysis of 5 controlled and 8 uncontrolled trials ( $\mathrm{n}=528$ participants) evaluating the effect of weight loss on UAE and proteinuria. ${ }^{11}$ Unlike most of these previous studies, our study was strengthened by having repeated 24hour urine sodium, urea nitrogen, and phosphorus measurements. Thus, we were able to examine the impact of changes in diet as well as changes in central obesity on UAE.

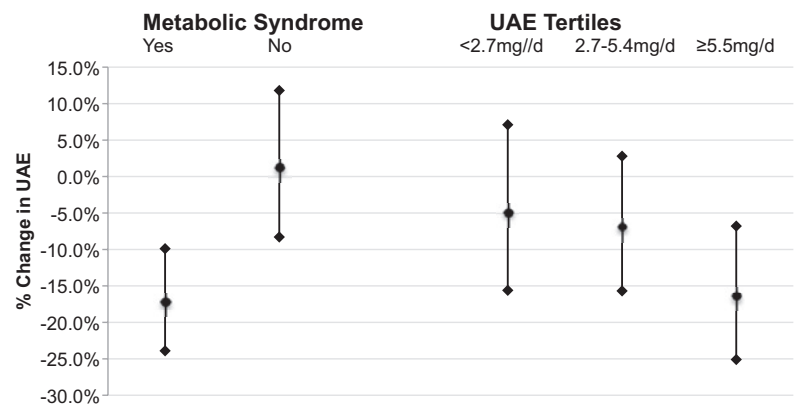

Figure 1. Effect of decreased waist circumference on urine albumin excretion (UAE) was modified by baseline metabolic syndrome and baseline UAE. Changes in UAE (95\% confidence interval) associated with a 1-SD decrease $(6.6 \mathrm{~cm})$ in waist circumference stratified by baseline metabolic syndrome and UAE tertile are shown. All models adjusted for age, site, African American race, baseline systolic blood pressure, current smoking, baseline In(UAE), changes in protein intake, and 24-hour urine phosphorus excretion. $P<0.05$ for both interactions (baseline metabolic syndrome and baseline UAE as a continuous variable) on change in waist circumference. 
The significant association we observed between changes in 24-hour urine phosphorus and UAE is novel and needs to be confirmed in other studies. These findings could reflect changes in total phosphorus intake, the sources of phosphorus being consumed, or less likely, changes in gut absorption or bone metabolism. In a normal physiologic state, 24hour urine phosphorus should approximate gut absorption of phosphorus. ${ }^{29,40}$ However, the bioavailability of phosphorus can be affected by vitamin D and calcium supplements, ${ }^{41,42}$ as well as the source of phosphorus. For example, inorganic phosphorus salts are believed to have much higher bioavailability $(90 \%$ $100 \%$ ) than naturally occurring forms of phosphorus $(40 \%-60 \%),{ }^{43-45}$ and food additives have been estimated to contribute up to $30 \%$ of the phosphorus consumed in the US diet. ${ }^{43}$ Phosphorus derived from animal protein typically is more bioavailable than vegetable protein because $\sim 75 \%$ of plant protein exists as phytate, which is not readily digestible by humans. ${ }^{46}$ Feeding studies have shown that there is lower 24-hour urinary phosphorus excretion while eating a diet with equivalent amounts of phosphorus from vegetable protein compared to animal protein, although no stool collections were done in these studies to confirm that this was due to differences in gut absorption. ${ }^{45,47}$ Thus, changes in 24-hour urine phosphorus excretion could be due to changes in the proportions of phosphorus derived from food processing, animal, and vegetable sources.

Cross-sectional studies have shown that UAE is highest in omnivores and lowest in vegans, ${ }^{48}$ and crossover studies of individuals with normal kidney function $^{49}$ and individuals with diabetic nephropathy ${ }^{50}$ have found lower rates of UAE while on vegetable protein diets compared with animal protein diets. Whether high protein intake of any type can cause long-term harm in individuals with normal kidney function remains unclear. ${ }^{2,24,33}$ A secondary analysis of OmniHeart (Optimal Macronutrient Intake Trial to Prevent Heart Disease), a randomized crossover feeding trial testing the effects of different macronutrient profiles on BP and lipid levels, found that a high-protein diet (25\% total calories) increased estimated glomerular filtration rate independent of changes in BP compared with the other 2 diets with lower protein (15\% total calories). ${ }^{24}$ In a randomized trial comparing a prescribed low-carbohydrate high-protein weight-loss diet to a prescribed low-fat weightloss diet, creatinine clearance was increased significantly at 3 months and 1 year (when adherence likely was greatest) in the low-carbohydrate high-protein diet group compared to the low-fat diet group. $^{22}$ However, the long-term effects of glomerular hyperfiltration related to high protein intake are unknown; studying the effects of diet on hard kidney disease or cardiovascular outcomes in a trial would require many years of follow-up or a high-risk population. Secondary analyses of the MDRD (Modification of Diet in Renal Disease) Study and a meta-analysis of dietary protein restriction studies suggest that restricting dietary protein intake may slow glomerular filtration rate decline in individuals with CKD. ${ }^{51,52}$

Although a direct causal link between excess dietary phosphorus intake and UAE remains speculative, in vitro and in vivo studies in animals and humans provide some supportive evidence that excess dietary phosphorus could have a detrimental effect on the endothelium. Bovine aortic endothelial cells exposed to higher phosphorus concentrations have been shown to have increased reactive oxygen species production and decreased nitric oxide production. ${ }^{53}$ These authors also reported that healthy volunteers who consumed a meal with $1,200 \mathrm{mg}$ of phosphorus (800 mg as sodium phosphate supplement) developed postprandial impaired flow-mediated dilatation, which correlated inversely with serum phosphorus levels. ${ }^{53}$ Observational studies have found that fasting serum phosphorus levels are associated with increased mortality even in individuals without $\mathrm{CKD},{ }^{27}$ and the phosphaturic hormone fibroblast growth factor 23 (FGF-23) is associated with albuminuria, CKD progression, ${ }^{54}$ incident heart failure, and all-cause mortality. ${ }^{55}$ However, self-reported dietary phosphorus intake is associated weakly with fasting serum phosphorus levels, making it difficult to extrapolate adverse associations with serum phosphorus to dietary phosphorus intake. ${ }^{56}$

High-phosphorus diets have been shown in animal models of CKD to cause renal injury (independent of protein intake). ${ }^{25}$ Studies of reducing phosphorus intake in humans have been largely confounded by concomitant reductions in protein intake. ${ }^{21}$ However, one nonrandomized study of protein restriction in proteinuric patients with CKD found an interaction between 24-hour urine phosphorus excretion and the antiproteinuric effect of a very low-protein diet. Individuals in this study who attained lower 24-hour urine phosphorus excretion while on the very low-protein diet $(0.3 \mathrm{~g} / \mathrm{kg}$ supplemented with keto-analogues) experienced greater reductions in proteinuria $(P$ for interaction $<0.001)$, ${ }^{57}$ providing some support for our findings.

Our study has a few limitations. First, this is an observational analysis of PREMIER, which was not originally designed to study the effects of behavioral interventions on UAE. Because multiple lifestyle factors changed simultaneously during the study, we cannot be certain that the observed associations were directly causal. We found no effect of the behavioral 
interventions on UAE, possibly because the adviceonly group also lost weight and had the most negative change in protein intake of the 3 groups. Second, we included only $59 \%$ of individuals originally randomly assigned in PREMIER, which mainly reflects the difficulty collecting repeated 24-hour urine collections. Third, participants had normal kidney function and most had baseline UAE $<10 \mathrm{mg} / \mathrm{d}$, above which seems to confer risk of cardiovascular disease and mortality. ${ }^{1-5}$ Although reduction in albuminuria is associated with decreased risk of kidney and cardiovascular disease, ${ }^{6,7}$ the effect of changes in UAE in this low range are unknown. Last, we adjusted for baseline supplement use in sensitivity analyses, but did not have information for changes in levels of parathyroid hormone, vitamin D, or FGF-23. Although we cannot definitively exclude the possibility that changes in 24-hour urine phosphorus excretion were due in part to changes in phosphorus metabolism rather than dietary intake, we believe this possibility is unlikely in individuals with normal kidney function. Strengths of our study include repeated dietary measurements based on 24-hour urine dietary biomarkers in a well-characterized cohort and the wide generalizability of our study because individuals with prehypertension or stage I hypertension make up approximately two-thirds of the US population.

In conclusion, our findings suggest that reducing excess adiposity and phosphorus intake may be important in lowering UAE. More research is needed to understand determinants of phosphorus absorption and excretion and whether excessive dietary phosphorus intake could be harmful to individuals with normal kidney function.

\section{ACKNOWLEDGEMENTS}

We thank the PREMIER participants for their dedication; Gayle Meltesen, Alan Bauck, and Dave Gibson for assistance in obtaining the laboratory data; and Gayane Yenokyan for reviewing an early draft.

Support: Dr Chang was supported by the National Institute of Diabetes and Digestive and Kidney Diseases grant T32DK007732.

Financial Disclosure: The authors declare that they have no other relevant financial interests.

\section{REFERENCES}

1. Astor BC, Matsushita K, Gansevoort RT, et al. Lower estimated glomerular filtration rate and higher albuminuria are associated with mortality and end-stage renal disease. A collaborative meta-analysis of kidney disease population cohorts. Kidney Int. 2011;79(12):1331-1340.

2. Gerstein HC, Mann JF, Yi Q, et al. Albuminuria and risk of cardiovascular events, death, and heart failure in diabetic and nondiabetic individuals. JAMA. 2001;286(4):421-426.

3. Hemmelgarn BR, Manns BJ, Lloyd A, et al. Relation between kidney function, proteinuria, and adverse outcomes. JAMA. 2010;303(5):423-429.
4. Kramer H, Jacobs DR Jr, Bild D, et al. Urine albumin excretion and subclinical cardiovascular disease. The Multi-Ethnic Study of Atherosclerosis. Hypertension. 2005;46(1):38-43.

5. Warnock DG, Muntner P, McCullough PA, et al. Kidney function, albuminuria, and all-cause mortality in the REGARDS (Reasons for Geographic and Racial Differences in Stroke) Study. Am J Kidney Dis. 2010;56(5):861-871.

6. de Zeeuw D, Remuzzi G, Parving HH, et al. Albuminuria, a therapeutic target for cardiovascular protection in type 2 diabetic patients with nephropathy. Circulation. 2004;110(8):921-927.

7. Schmieder RE, Mann JF, Schumacher H, et al. Changes in albuminuria predict mortality and morbidity in patients with vascular disease. J Am Soc Nephrol. 2011;22(7):1353-1364.

8. Henegar JR, Bigler SA, Henegar LK, Tyagi SC, Hall JE. Functional and structural changes in the kidney in the early stages of obesity. J Am Soc Nephrol. 2001;12(6):1211-1217.

9. Griffin KA, Kramer H, Bidani AK. Adverse renal consequences of obesity. Am J Physiol Renal Physiol. 2008;294(4):F685F696.

10. Yamagata K, Ishida K, Sairenchi T, et al. Risk factors for chronic kidney disease in a community-based population: a 10year follow-up study. Kidney Int. 2007;71(2):159-166.

11. Afshinnia F, Wilt TJ, Duval S, Esmaeili A, Ibrahim HN. Weight loss and proteinuria: systematic review of clinical trials and comparative cohorts. Nephrol Dial Transplant. 2010;25(4): 1173-1183.

12. Chang A, Van Horn L, Jacobs D, Liu K, Bibbins-Domingo $\mathrm{K}$. Lifestyle behaviors and incident chronic kidney disease (CKD): the CARDIA Study [NKF abstract 56]. Am J Kidney Dis. 2011; 57(4):B30.

13. Lin J, Fung TT, Hu FB, Curhan GC. Association of dietary patterns with albuminuria and kidney function decline in older white women: a subgroup analysis from the Nurses' Health Study. Am J Kidney Dis. 2011;57(2):245-254.

14. Jacobs DR Jr, Gross MD, Steffen L, et al. The effects of dietary patterns on urinary albumin excretion: results of the Dietary Approaches to Stop Hypertension (DASH) trial. Am J Kidney Dis. 2009;53(4):638-646.

15. Saiki A, Nagayama D, Ohhira M, et al. Effect of weight loss using formula diet on renal function in obese patients with diabetic nephropathy. Int J Obes (Lond). 2005;29(9):1115-1120.

16. Solerte SB, Fioravanti M, Schifino N, Ferrari E. Effects of diet-therapy on urinary protein excretion albuminuria and renal haemodynamic function in obese diabetic patients with overt nephropathy. Int J Obes. 1989;13(2):203-211.

17. Navarro-Diaz M, Serra A, Romero R, et al. Effect of drastic weight loss after bariatric surgery on renal parameters in extremely obese patients: long-term follow-up. J Am Soc Nephrol. 2006; 17(12) (suppl 3): S213-S217.

18. Chagnac A, Weinstein T, Herman M, Hirsh J, Gafter U, Ori Y. The effects of weight loss on renal function in patients with severe obesity. J Am Soc Nephrol. 2003;14(6):1480-1486.

19. Agrawal V, Khan I, Rai B, et al. The effect of weight loss after bariatric surgery on albuminuria. Clin Nephrol. 2008;70(3): 194-202.

20. Morales E, Valero MA, Leon M, Hernandez E, Praga M. Beneficial effects of weight loss in overweight patients with chronic proteinuric nephropathies. Am J Kidney Dis. 2003;41(2): 319-327.

21. Levey AS, Adler S, Caggiula AW, et al. Effects of dietary protein restriction on the progression of advanced renal disease in the Modification of Diet in Renal Disease Study. Am J Kidney Dis. 1996;27(5):652-663.

22. Friedman AN, Ogden LG, Foster GD, et al. Comparative effects of low-carbohydrate high-protein versus low-fat diets on the kidney. Clin J Am Soc Nephrol. 2012;7(7):1103-1111. 
23. Knight EL, Stampfer MJ, Hankinson SE, Spiegelman D, Curhan GC. The impact of protein intake on renal function decline in women with normal renal function or mild renal insufficiency. Ann Intern Med. 2003;138(6):460-467.

24. Juraschek SP, Appel LJ, Anderson CA, Miller ER III. Effect of a high-protein diet on kidney function in healthy adults: results from the OmniHeart trial. Am J Kidney Dis. 2013;61(4):547-554.

25. Haut LL, Alfrey AC, Guggenheim S, Buddington B, Schrier N. Renal toxicity of phosphate in rats. Kidney Int. 1980;17(6):722731.

26. Lee H, Oh SW, Heo NJ, et al. Serum phosphorus as a predictor of low-grade albuminuria in a general population without evidence of chronic kidney disease. Nephrol Dial Transplant. 2012;27(7):2799-2806.

27. Tonelli M, Sacks F, Pfeffer M, Gao Z, Curhan G; Cholesterol and Recurrent Events Trial Investigators. Relation between serum phosphate level and cardiovascular event rate in people with coronary disease. Circulation. 2005;112(17):2627-2633.

28. Dhingra R, Sullivan LM, Fox CS, et al. Relations of serum phosphorus and calcium levels to the incidence of cardiovascular disease in the community. Arch Intern Med. 2007;167(9):879-885.

29. Houston J, Isakova T, Wolf M. Phosphate metabolism and fibroblast growth factor 23 in chronic kidney disease. In: Kopple J, Massry S, Kalantar-Zadeh K, eds. Nutritional Management of Renal Disease. 3rd ed. Waltham, MA: Academic Press; 2012:285307.

30. Appel LJ, Champagne CM, Harsha DW, et al. Effects of comprehensive lifestyle modification on blood pressure control: main results of the PREMIER clinical trial. JAMA. 2003;289(16): 2083-2093.

31. Maroni BJ, Steinman TI, Mitch WE. A method for estimating nitrogen intake of patients with chronic renal failure. Kidney Int. 1985;27(1):58-65.

32. Masud T, Manatunga A, Cotsonis G, Mitch WE. The precision of estimating protein intake of patients with chronic renal failure. Kidney Int. 2002;62(5):1750-1756.

33. Halbesma N, Bakker SJ, Jansen DF, et al. High protein intake associates with cardiovascular events but not with loss of renal function. J Am Soc Nephrol. 2009;20(8):1797-1804.

34. Scialla JJ, Appel LJ, Astor BC, et al. Net endogenous acid production is associated with a faster decline in GFR in African Americans. Kidney Int. 2012;82(1):106-112.

35. National Cholesterol Education Program (NCEP) Expert Panel on Detection, Evaluation, and Treatment of High Blood Cholesterol in Adults (Adult Treatment Panel III). Third Report of the National Cholesterol Education Program (NCEP) Expert Panel on Detection, Evaluation, and Treatment of High Blood Cholesterol In Adults (Adult Treatment Panel III) final report. Circulation. 2002;106(25):3143-3421.

36. Matthews DR, Hosker JP, Rudenski AS, Naylor BA, Treacher DF, Turner RC. Homeostasis model assessment: insulin resistance and beta-cell function from fasting plasma glucose and insulin concentrations in man. Diabetologia. 1985;28(7):412-419.

37. Liu K, Stamler J. Assessment of sodium intake in epidemiological studies on blood pressure. Ann Clin Res. 1984;16(suppl 43):49-54.

38. Pouliot MC, Despres JP, Lemieux S, et al. Waist circumference and abdominal sagittal diameter: best simple anthropometric indexes of abdominal visceral adipose tissue accumulation and related cardiovascular risk in men and women. Am J Cardiol. 1994;73(7):460-468.

39. Pak CY, Odvina CV, Pearle MS, et al. Effect of dietary modification on urinary stone risk factors. Kidney Int. 2005;68(5): 2264-2273.
40. Spencer H, Menczel J, Lewin I, Samachson J. Effect of high phosphorus intake on calcium and phosphorus metabolism in man. J Nutr. 1965;86:125-132.

41. Schiller LR, Santa Ana CA, Sheikh MS, Emmett M, Fordtran JS. Effect of the time of administration of calcium acetate on phosphorus binding. N Engl J Med. 1989;320(17):1110-1113.

42. Ramirez JA, Emmett M, White MG, et al. The absorption of dietary phosphorus and calcium in hemodialysis patients. Kidney Int. 1986;30(5):753-759.

43. Uribarri J, Calvo MS. Hidden sources of phosphorus in the typical American diet: does it matter in nephrology? Semin Dial. 2003;16(3):186-188.

44. Bell RR, Draper HH, Tzeng DY, Shin HK, Schmidt GR. Physiological responses of human adults to foods containing phosphate additives. $J$ Nutr. 1977;107(1):42-50.

45. Karp HJ, Vaihia KP, Karkkainen MU, Niemisto MJ, Lamberg-Allardt CJ. Acute effects of different phosphorus sources on calcium and bone metabolism in young women: a whole-foods approach. Calcif Tissue Int. 2007;80(4):251-258.

46. Iqbal TH, Lewis KO, Cooper BT. Phytase activity in the human and rat small intestine. Gut. 1994;35(9):1233-1236.

47. Moe SM, Zidehsarai MP, Chambers MA, et al. Vegetarian compared with meat dietary protein source and phosphorus homeostasis in chronic kidney disease. Clin J Am Soc Nephrol. 2011;6(2): 257-264

48. Wiseman MJ, Hunt R, Goodwin A, Gross JL, Keen H, Viberti GC. Dietary composition and renal function in healthy subjects. Nephron. 1987;46(1):37-42.

49. Kontessis PA, Bossinakou I, Sarika L, et al. Renal, metabolic, and hormonal responses to proteins of different origin in normotensive, nonproteinuric type I diabetic patients. Diabetes Care. 1995;18(9):1233.

50. Azadbakht L, Esmaillzadeh A. Soy-protein consumption and kidney-related biomarkers among type 2 diabetics: a crossover, randomized clinical trial. J Ren Nutr. 2009;19(6):479-486.

51. Levey AS, Greene T, Beck GJ, et al. Dietary protein restriction and the progression of chronic renal disease: what have all of the results of the MDRD Study shown? Modification of Diet in Renal Disease Study Group. J Am Soc Nephrol. 1999;10(11): 2426-2439.

52. Kasiske BL, Lakatua JD, Ma JZ, Louis TA. A meta-analysis of the effects of dietary protein restriction on the rate of decline in renal function. Am J Kidney Dis. 1998;31(6):954-961.

53. Shuto E, Taketani Y, Tanaka R, et al. Dietary phosphorus acutely impairs endothelial function. J Am Soc Nephrol. 2009;20(7): 1504-1512.

54. Lundberg S, Qureshi AR, Olivecrona S, Gunnarsson I, Jacobson SH, Larsson TE. FGF23, albuminuria, and disease progression in patients with chronic IgA nephropathy. Clin J Am Soc Nephrol. 2012;7(5):727-734.

55. Parker BD, Schurgers LJ, Brandenburg VM, et al. The associations of fibroblast growth factor 23 and uncarboxylated matrix Gla protein with mortality in coronary artery disease: the Heart and Soul Study. Ann Intern Med. 2010;152(10):640-648.

56. de Boer IH, Rue TC, Kestenbaum B. Serum phosphorus concentrations in the Third National Health and Nutrition Examination Survey (NHANES III). Am J Kidney Dis. 2009;53(3):399407.

57. Di Iorio BR, Bellizzi V, Bellasi A, et al. Phosphate attenuates the anti-proteinuric effect of very low-protein diet in CKD patients. Nephrol Dial Transplant. 2013;28(3):632-640. 